\title{
An epidemiological study of Wolf-Hirschhorn syndrome: life expectancy and cause of mortality
}

\author{
N L Shannon, E L Maltby, A S Rigby, O W J Quarrell
}

\begin{abstract}
Objective-Early research into WolfHirschhorn syndrome (WHS) described a high mortality and no relationship between deletion size and phenotype. This may need to be revised in the light of improved cytogenetic resolution and medical care. We have collected epidemiological data to allow the calculation of birth incidence and mortality figures. In addition, we have investigated the possibility of a relationship between deletion size and mortality.

Method-Information relating to past and present cases diagnosed in the UK was collected by multiple ascertainment.

Results-A total of 159 cases were collected. The status (alive or dead) was determined for 146, of whom 96 are alive, 37 had died, and 13 were detected on prenatal diagnostic tests. A minimum birth incidence of 1 in 95896 was calculated. The crude infant mortality rate was $17 \%$ (23/132) and in the first two years of life the mortality rate was $21 \%(28 / 132)$. Cases with large de novo deletions (proximal to and including p15.2) were more likely to have died than those with smaller deletions (odds ratio $=5.7,95 \% \mathrm{CI}=1.7-19.9$ ) after adjusting for age. A comparison of survival curves for de novo deletions and translocations did not show a statistically significant difference $(p=0.11)$. The median survival time for de novo deletions was 34+ years while for translocation cases it was $18+$ years.

Conclusions-The mortality rate is lower than previously reported. There is a statistically significant relationship between deletion size and overall risk of death in de novo deletion cases. The difference in survival curves between de novo deletions and translocations is not statistically significant. (F Med Genet 2001;38:674-679)
\end{abstract}

Keywords: Wolf-Hirschhorn syndrome; chromosome 4; mortality

Wolf-Hirschhorn syndrome (WHS) is a chromosome deletion syndrome with a well delineated phenotype. It was first described by Hirschhorn and Cooper ${ }^{1}$ in 1961 in a child with midline fusion defects in association with deletion of a B group chromosome. Wolf et al described a similar case in 1965 and this was published together with Hirschhorn's original case. The vast majority of cases are the result of hemizygosity of $4 \mathrm{p} 16.3$ and a $165 \mathrm{~kb}$ critical region was delineated in 1997, based on children with overlapping deletions. ${ }^{3}$
Typically these children have pre- and postnatal growth retardation, feeding difficulties, developmental delay, and often epilepsy. They have a characteristic facial appearance with a prominent glabella, hypertelorism, high arched eyebrows, broad nasal bridge, and micrognathia. Congenital anomalies include midline defects (cleft lip/palate, hypospadias, and scalp defects), congenital heart disease, renal and ophthalmic anomalies (iris coloboma, microphthalmia, strabismus) and skeletal abnormalities. ${ }^{4-6}$

Several early studies stated that there was no relationship between the severity of the phenotype and deletion size. ${ }^{4-9}$ This would suggest that the mortality should be similarly independent. The possibility of a relationship between deletion size and phenotype has recently become topical again with conflicting opinions in published studies. ${ }^{10-12}$

A review of 43 cases of WHS in 1976 gave a mortality of $34 \%$ in the first two years of life. ${ }^{4}$ This figure is still widely quoted in standard genetic texts and is used by medical staff when counselling parents about long term prognosis. There are several reasons why this might need to be revised. Firstly, improvements in cytogenetic techniques and the advent of fluorescence in situ hybridisation (FISH) have enabled the detection of a cohort of children with small or submicroscopic deletions. This increase in the range of deletion sizes identified may have widened the phenotypic spectrum. The observation that submicroscopic deletions of $4 \mathrm{p}$ have now been reported in a number of children with Pitt-Rogers-Danks syndrome, ${ }^{13-15}$ a milder phenotype with similar facial dysmorphism, lends weight to this theory. Secondly, we would expect improvements in medical and surgical care over the last 20 years to have made an impact on survival.

As a result of these observations, we undertook a national survey. The aim was to collect information about the life expectancy and cause of death in cytogenetically or molecularly confirmed cases of WHS in the United Kingdom and to investigate the possibility of a correlation between deletion size and mortality.

\section{Methods}

\section{DATA COLLECTION}

The study was approved by the local research ethics committee. Cases were ascertained through three main sources: cytogenetic departments, the Chromosome Abnormality Database (CAD) based in Oxford, and the patient support group.

A survey form was sent to all National Heath Service (NHS) cytogenetic laboratories in the UK and one private laboratory. Details of all WHS cases on their records were requested,
19 July 2001

Accepted for publication

20 July 2001 
including the karyotype, date of birth, and referring clinician. Clinicians were asked whether their patient was still alive or to give the date and cause of death. Where a clinician was no longer following up a patient, attempts were made to ascertain their status through the general practitioner. Some laboratories preferred to contact referring clinicians themselves to collect the necessary clinical data, but in the majority of cases letters were sent from our department. Of the 29 cytogenetic laboratories surveyed, 21 returned forms. Information from a further five regional centres was obtained through their clinical genetics departments. Of the remaining three laboratories, only one was part of a regional service.

The Chromosome Abnormality Database provided details of 61 cases. When compared to the results of the laboratory survey, 19 of these represented additional cases and the laboratories concerned were contacted for further details.

The Wolf-Hirschhorn Syndrome Support Group is a voluntary organisation for families in the UK. Over 70 members were contacted through the group and asked to provide details about their children, including the name of their general practitioner and hospital consultant. Forty four families responded to this request.

During this process of data collection, all NHS regional genetics services were contacted to obtain data about a patient's status (alive or dead) and enquiries about any additional cases were made at that time. As a result, two cases were ascertained where a submicroscopic deletion was detected before the advent of FISH, using molecular techniques.

As part of a parallel clinical study, 47 of the patients have had repeat chromosome analysis performed in the North Trent Cytogenetic Laboratory. In these cases, the new karyotype was used to provide a more detailed delineation of the breakpoint.

\section{STATISTICAL ANALYSIS}

Kaplan-Meier survival curves were estimated using software contained within the GLIM4 macro library ${ }^{16}$ and were compared using Gehan's test statistic. The odds of death for

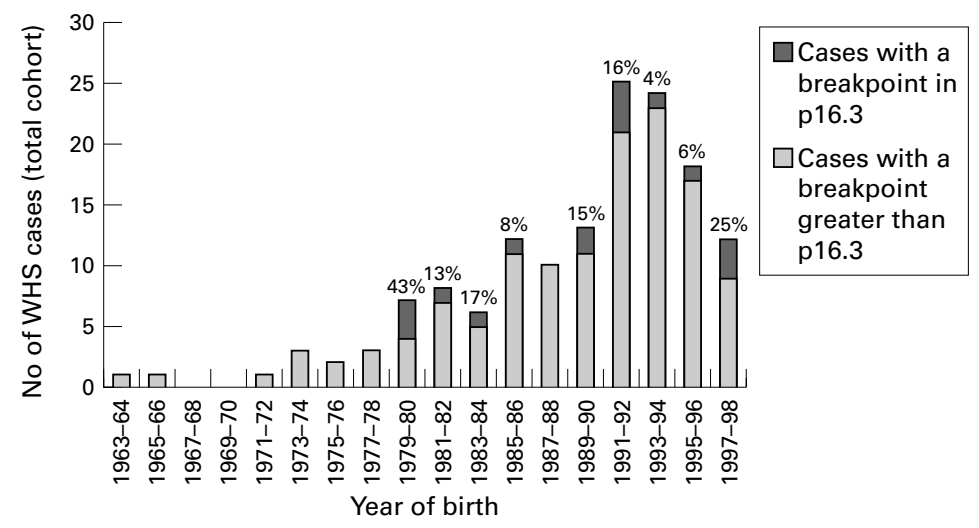

Figure 1 The number of diagnosed cases born per year in the total cohort of 146 represents the apparent birth incidence. Cases with a breakpoint within p16.3 and their percentage of the total in each two year column are shown separately to illustrate the apparent incidence of small and submicroscopic deletions over time. patients with small (breakpoint p15.3 or more distal) and large deletions (p15.2 or more proximal) were calculated since this was a cross sectional, retrospective study. The odds ratio is used as an approximation to the relative risk. ${ }^{17}$ Ninety five percent confidence limits were determined according to Morris and Gardner. ${ }^{18}$

\section{Results}

INCIDENCE

During the course of the study, 159 cases were collected by multiple ascertainment, of which 92 were provided by only one of the three main sources, 56 were collected from two sources, and 11 from all three. Of these, 115/159 $(72.3 \%)$ were de novo deletions, 32/159 $(20.1 \%)$ were translocations, of which $4 / 32$ were de novo, and $12 / 159(7.5 \%)$ were other rearrangements. The proportion of translocations is slightly higher than in other studies $(10-15 \%) .{ }^{19} 20$ There were 95 females and 64 males in the total cohort. Of the infants who reached term gestation, 75 were female and 58 were male. A female preponderance has been shown in previous studies. ${ }^{20-22}$ The oldest female in our series is 35 years while the oldest male is 34 years of age.

The minimum birth incidence can be calculated from the number of WHS cases born in the 10 years between 1989 and 1998 and the number of live births in the United Kingdom over this period. ${ }^{23}{ }^{24}$ This gives a minimum birth incidence of 1 in 95 896. This compares with a previous estimate of 1 in $50000 .^{20}$ Fig 1 shows the number of diagnosed cases born in two year intervals. Given that WHS is a relatively rare condition, this varies from year to year and has increased over time, reaching a peak of 24 cases born between 1991 and 1992 .

It was possible to collect the status (alive or dead) in 146 cases, of which 96/146 cases were alive, 37/146 were dead, and the remaining 13 were prenatal diagnostic tests which all proceeded to termination. Since there may be a significant delay in diagnosis in some cases, the date of birth may not accurately reflect clinical ascertainment. Death decreases the chance of a retrospective diagnosis and of the 37 children who had died only two were diagnosed more than 1 year after birth, one at 18 months old and another at 11 years. Fig 2 shows the data for the cohort of cases who are alive. When the number of diagnosed cases born per two year interval (fig 2A) is compared with the number of diagnoses made (fig $2 \mathrm{~B}$ ), a trend is seen for an increasing number of diagnoses made both retrospectively and soon after birth in the 1990s. Of the 96 cases that are alive, 23 were diagnosed more than a year after birth, of whom eight had breakpoints within p16.3. Cases with breakpoints within p16.3, born in the 1980 s, were almost exclusively diagnosed in the 1990s. This is because of improvements in cytogenetic resolution, the introduction of FISH into routine practice, and an increasing awareness of the phenotype.

\section{MORTALITY}

Once the cases diagnosed on prenatal diagnostic testing were removed, $27.8 \%(37 / 133)$ of the patients had died. To provide as accurate a 

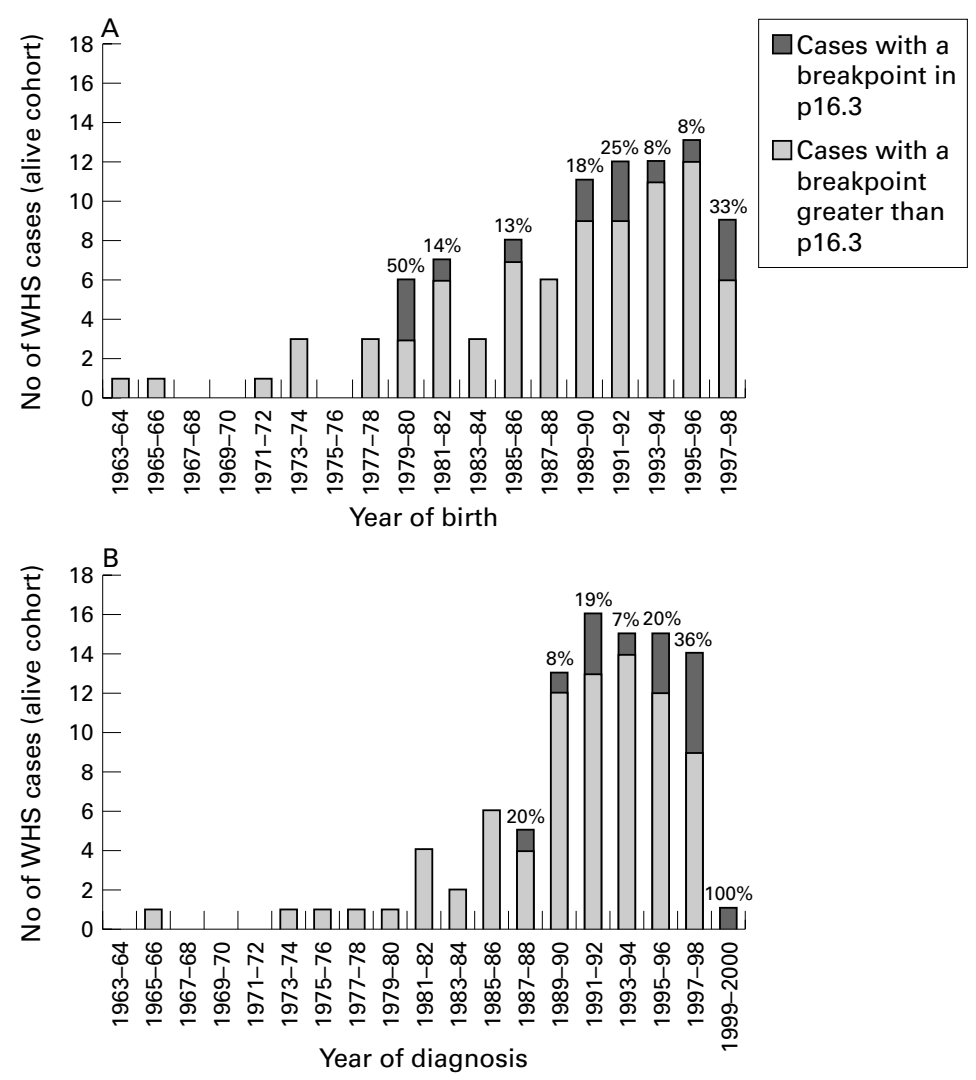

Figure 2 The number of diagnosed cases born per year in the live cohort $(A)$ shows a steady increase in the apparent birth incidence reflecting improved ascertainment. The number of diagnoses made per year in the same cohort (B), however, shows a sharp increase in the 1990s. This indicates that a substantial number of diagnoses have been made both retrospectively and soon after birth as a result of improved cytogenetic resolution and clinical ascertainment. The number of cases with a breakpoint within p16.3 and their percentage of each two year column is shown to indicate the impact of FISH on clinical ascertainment.

reflection of current medical care as possible, the same calculation was performed for children born over the last 10 years. Between 1989 and 1998, 79 children with WHS were born, of whom 23 subsequently died (29.1\%).

Of the 37 children who had died, it was possible to ascertain the age at death in 36 , giving a cohort of 132 live births where age at death or status were known. The age at death is summarised in table 1 . Of these, $63.9 \%(23 / 36)$ died in the first year of life. Expressing this per number of live births with WHS gives an infant mortality rate of $17.4 \%$ (23/132). Only one previous study has given a mortality rate in WHS. ${ }^{4}$ This was calculated for the first two years of life and gave a figure of $34 \%$. In our study group, 28/36 $(77.8 \%)$ deaths occurred in the first two years of life, giving a mortality in this period of $21 \%(28 /$ 132). This overall figure includes all sizes of de novo deletion and translocations.

Survival curves for de novo deletion and translocation cases are shown in fig 3. A greater proportion of the translocations compared to de novo deletions died within the first five years of life. However, the difference between the two survival curves was not statistically significant ( $p=0.11$ by Gehan's test). Neither of the survival curves reached $50 \%$ which means that the median survival time for de novo deletions was greater than 34 years, while for translocation cases it was greater than 18 years.
Table 1 Age at death in study group

\begin{tabular}{ll}
\hline Age at death & Number $(n=36)$ \\
\hline$<24$ hours & 6 \\
24 hours -28 days & 12 \\
$>28$ days -1 year & 5 \\
$>1$ year-2 years & 5 \\
$>2-5$ years & 4 \\
$>5-10$ years & 2 \\
$>10$ years & 2
\end{tabular}

Some of the older karyotype reports did not contain a breakpoint because they were performed on unbanded chromosomes. Chromosome analysis was repeated in 47 cases as part of a clinical study and these more recent reports were used to minimise this loss of data. In 15/47 the original breakpoint was confirmed, in 12/47 a more detailed breakpoint resulted, in 19/47 the breakpoint was redefined, and in 1/47 lymphocyte culture failed. Of the cases where the breakpoint was changed, 6/19 moved from the large to the small deletion size group and 2/19 moved from the small to large group.

As a result of this process there were breakpoints for $141 / 146$ cases where the status was known. Table 2 shows the breakpoints for this cohort of cases, divided into de novo deletions, translocations, and other rearrangements. It is interesting to note that out of 17 cases with a breakpoint within p16.3, only two have died, neither of whom had a de novo deletion. The tendency towards larger deletions in cases detected prenatally may reflect the limits of cytogenetic resolution in prenatal samples or ascertainment bias.

Removing translocations and other rearrangements allows a comparison of the proportion of deaths in different deletion sizes, without the possible effect of any coexisting trisomy. Fig 4 summarises the mortality data by breakpoint in de novo deletion cases; it shows a marked difference in the number of deaths between those with large deletions (breakpoint distal to and including p15.2) and those with small deletions (p15.3-p16.3). In the large deletion group, $17 / 33(51.5 \%)$ had died, compared with $6 / 62(9.7 \%)$ in the small deletion group. This gives an overall crude odds of death of 9.9 (95\% CI=3.4-29.2). Since improvements in cytogenetic techniques may have resulted in a larger proportion of young cases in the small deletion group, we also calculated an age adjusted odds ratio which was 5.7 (95\% CI=1.7-19.9). This shows that although age is a confounding factor, the results remain statistically significant when this is taken into account.

The definitions for small and large deletions were chosen on the basis that they showed the largest difference in the risk of death. Analysis using more distal and proximal cut off points between the two deletion size groups shows the same trend (data not shown). Karyotypes with low quality banding and a breakpoint of p15 cannot be accurately placed in one of these two groups. The differences in mortality between the two groups remain statistically significant whether this small number of subjects are allocated to the small or large deletion group. 


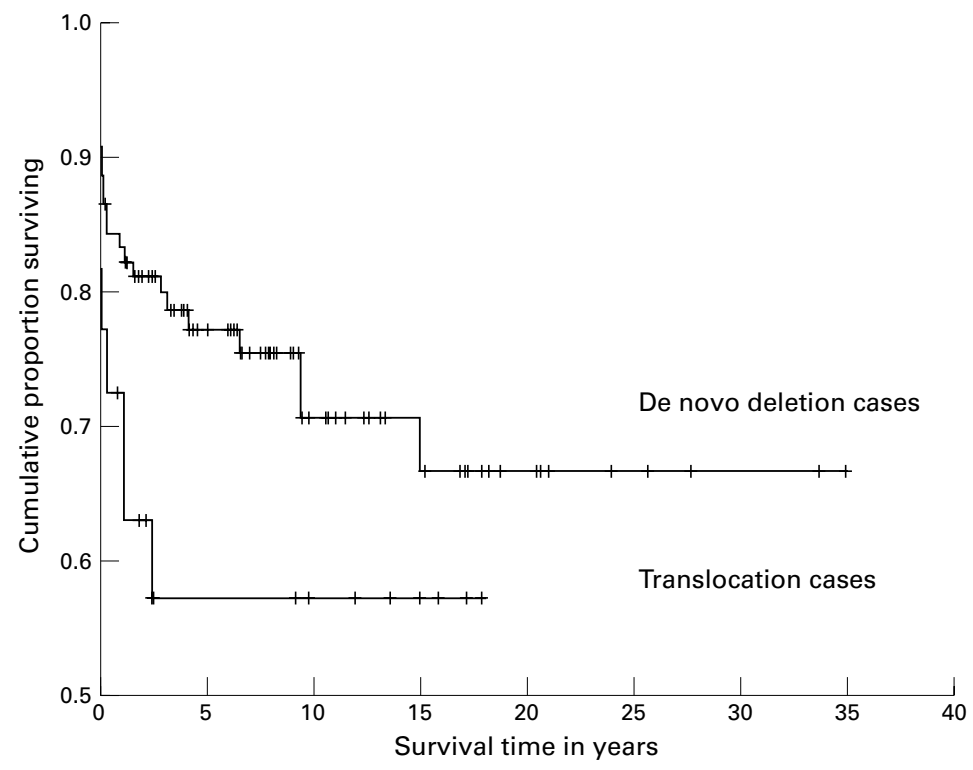

Figure 3 Survival curves for de novo deletion and translocation cases. The censored observations (cases who have not yet died) are indicated (+).

CAUSE OF DEATH

The cause of death was ascertained in 32/37 dead children and is summarised in table 3. Seventeen children died as a result of birth anoxia, withdrawal of treatment after premature delivery, or congenital anomalies. Congenital heart disease included one case of tetralogy of Fallot, two with a ventricular septal defect and patent ductus arteriosus, one with an ostium secundum atrial septal defect, and a complex case involving a double outlet single ventricle with a single atrioventricular valve, large aorta, and small posterior pulmonary artery with pulmonary valve stenosis. In addition to congenital heart disease, other anomalies included dysplastic kidneys, renal hypoplasia, diaphragmatic hernia, and pulmonary hypoplasia.

Eight patients died as the result of a lower respiratory tract infection which was complicated by seizures and probable aspiration in two cases. The ages of these children ranged from 11 days to 6 years 7 months. The five sudden unexplained deaths ranged in age from 1 year to 15 years. Three of these children had necropsies, which failed to identify a cause.

\section{Discussion}

The cases were collected using multiple ascertainment. There was only one regional genetics service where it was not possible to collect data

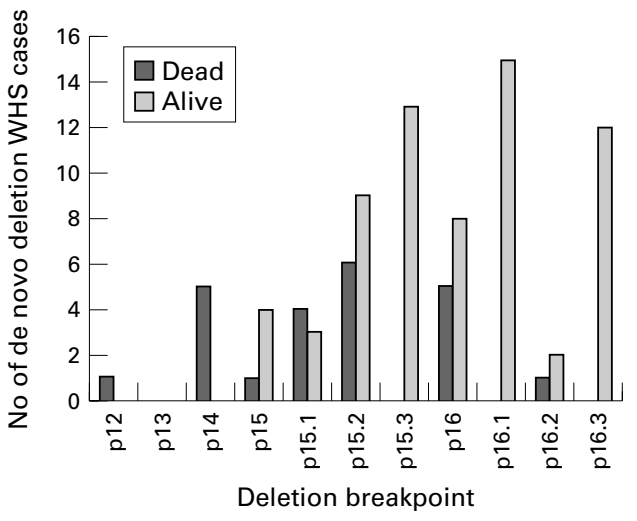

Figure 4 Status (alive or dead) and breakpoint in the de novo deletion group, showing a higher number of deaths in large deletions.

from either the clinical or laboratory service, although cases from this area were collected through other sources. As a result, we believe we have achieved a high ascertainment, although there are several potential sources of bias relating to the study design and collection of cases.

Firstly, the retrospective collection of data results in an unavoidable under-ascertainment of older cases in the study, especially those who have died and are no longer under the care of clinical genetics services. Many laboratories moved onto computer database systems in the late 1980 s to early 1990 s or have changed systems in the last 10 years. This can lead to difficulties in retrieving old records and the amount of data lost varies between centres. This will be responsible for part of the increasing ascertainment over time seen in fig 1 .

Secondly, older cases were more likely to have unbanded karyotypes. Without breakpoints, these cases could not be assigned to the large or small deletion group and so they were not included in this part of the analysis. This problem was overcome in some cases by a parallel clinical study during which participants had repeat chromosome analysis in the North Trent Cytogenetics Laboratory. This karyotype provided a more precise breakpoint in 12/47 cases but also changed the breakpoint in 19/47 cases, although only eight of these moved from one deletion size group to another.

As well as biases introduced by the study design, there will have been true changes in clinical ascertainment and mortality over time. Improvements in chromosome analysis and the advent of FISH have enabled the detection of

Table 2 Deletion size, type, and status (alive or dead) in the cohort of 141 cases

\begin{tabular}{|c|c|c|c|c|c|c|c|c|c|}
\hline \multirow[b]{2}{*}{$\begin{array}{l}\text { Breakpoint } \\
\text { on } 4 p\end{array}$} & \multicolumn{3}{|c|}{ Detected on prenatal diagnostic testing } & \multicolumn{3}{|l|}{ Dead } & \multicolumn{3}{|l|}{ Alive } \\
\hline & $\begin{array}{l}\text { De novo } \\
\text { deletion }\end{array}$ & Translocation & Other & $\begin{array}{l}\text { De novo } \\
\text { deletion }\end{array}$ & Translocation & Other & $\begin{array}{l}\text { De novo } \\
\text { deletion }\end{array}$ & Translocation & Other \\
\hline p12 & & & & 1 & & & & & \\
\hline p13 & 1 & & & & & & & & \\
\hline p14 & 1 & & & 5 & & & & & \\
\hline p15 & & 1 & 1 & 1 & 1 & 1 & 4 & 1 & 2 \\
\hline p15.1 & 1 & 1 & & 4 & & & 3 & & \\
\hline p 15.2 & 3 & & & 6 & 5 & & 9 & 1 & 1 \\
\hline p15.3 & & & & & 1 & & 19 & 4 & 3 \\
\hline $\mathrm{p} 16$ & 1 & 1 & & 5 & 1 & & 8 & 2 & \\
\hline p16.1 & & & & & 2 & & 15 & 3 & 1 \\
\hline p16.2 & & & & 1 & & & 2 & & 1 \\
\hline $\mathrm{p} 16.3$ & & & & & 1 & 1 & 12 & 3 & \\
\hline Total & 7 & 3 & 1 & 23 & 11 & 2 & 72 & 14 & 8 \\
\hline
\end{tabular}


Table 3 Causes of death in the study group

\begin{tabular}{ll}
\hline Cause of death & Number $(n=32)$ \\
\hline Lower respiratory tract infection & $8(25 \%)$ \\
Multiple congenital anomalies & $5(15.6 \%)$ \\
Sudden unexplained death & $5(15.6 \%)$ \\
Congenital heart disease & $5(15.6 \%)$ \\
Anoxia at birth & $3(9.4 \%)$ \\
Withdrawal of treatment after premature & $3(9.4 \%)$ \\
$\quad$ delivery & $1(3.1 \%)$ \\
$\begin{array}{l}\text { Renal anomalies } \\
\text { Peritonitis }\end{array}$ & $1(3.1 \%)$ \\
Complications secondary to measles & $1(3.1 \%)$ \\
$\quad$ infection & \\
\hline
\end{tabular}

children with small or submicroscopic deletions. We would expect this to have increased the number of diagnoses, both retrospectively and soon after birth, and the proportion of children with small deletions. Fig 2 shows that while there has been a steady increase in the apparent birth incidence, the number of cases diagnosed per year increased dramatically in the 1990s. It is not possible to deduce the number of truly submicroscopic deletions from the karyotype reports since FISH is often used to confirm a diagnosis even when a deletion is cytogenetically visible, but the advent of this new technology has clearly had an impact on the number of small deletions diagnosed. There has also been an increase in the number of distal deletions, reflecting increasing awareness of the phenotype, use of genetic services, and improvements in cytogenetic resolution. Despite the number of retrospective diagnoses, children with small deletions tended to be younger than those with large deletions. The overall risk of death in small and large deletion groups was adjusted for age to take this confounding factor into account.

In addition, cases with distal deletions are more likely to be diagnosed than small deletions. This is largely because they are easily identified on routine cytogenetic analysis. Two recent studies have found that children with large deletions are more likely to have major congenital anomalies which may further increase the ascertainment in these cases. ${ }^{11}{ }^{11}$ While it might seem that death and a resulting necropsy will increase the likelihood of diagnosis in cases with large deletions, the small number of diagnoses made more than one year after birth in the cohort who had died $(2 / 37,5 \%)$ compared with the live cohort $(23 / 96,24 \%)$ indicates that some cases may die before a diagnosis is reached. This will, to some extent, decrease the relative bias towards the diagnosis of large deletions.

Conversely, children with small or submicroscopic deletions are less likely to be diagnosed since their deletions may not be detected in the absence of clinical suspicion. Clinicians may fail to recognise the milder phenotype which can be associated with these deletions, originally described as Pitt-Rogers-Danks syndrome. As this study shows that children with small deletions have a lower mortality, this will result in an overestimation of the true mortality rate.

Lastly, the subjects in the study reflect medical care over the last 35 years which has changed dramatically. We would expect a true improvement in the morbidity and mortality as a result, with the youngest children most accurately reflecting current survival. With this in mind, the proportion of children born between 1989 and 1998 who have died was calculated $(29.1 \%)$ and is in fact similar to the total cohort $(27.8 \%)$, although this in part reflects the increased ascertainment over this time period. It is possible that advances in the prenatal detection of multiple congenital anomalies and the quality of prenatal chromosome analysis may have led to a reduction in the number of live births with multiple congenital anomalies or large chromosome deletions, but we would expect the impact of this on mortality to be small.

This is the first large scale survey of this type for WHS and as a result it provides a more accurate estimate of the minimum birth incidence than has previously been available (approximately 1 in 96000 ). This figure will be an underestimate of the true incidence, given that it is not possible to achieve complete ascertainment of diagnosed cases and some cases will remain undiagnosed for the reasons discussed.

Although this study shows an improvement in the mortality in the first two years of life from $34 \%^{4}$ to $21 \%$, over the last 24 years, more significant changes are seen when deletion size is taken into account. These results show that children with large deletions have a high overall risk of death compared to children with small deletions $(51.5 \% v 9.7 \%)$ and this is confirmed by an age adjusted odds ratio of 5.7 (95\% CI=1.7-19.9).

The survival curves show that after the age of two years, the number of deaths falls dramatically. Children who reach 2 years of age will have lived through this period of high risk and will have a significantly improved outlook. The high infant mortality rate $(17 \%)$ is not surprising when the most common causes of death are considered. In $17 / 32(53.1 \%)$ cases, death was the result of congenital anomalies, birth anoxia, or withdrawal of neonatal intensive care support after diagnosis. In addition, these children are prone to serious respiratory infections in early childhood. Of the children who died as a result of respiratory tract infections, 5/7 were below the age of 2 years. None of the surviving children had a breakpoint more proximal than p15, suggesting that larger deletions are incompatible with life.

It is not possible to identify the reason for the high overall risk of death in large deletion cases from this study. Recent studies, however, have found that children with large deletions are more likely to have major congenital anomalies. These not only have a significant morbidity and mortality in their own right, but also increase the subject's susceptibility to infection. This would support the proposition that WHS in an example of a true contiguous gene deletion syndrome, the alternative theory being hemizygosity or mutations in a single gene. ${ }^{26} 27$

The survival curves for de novo deletion cases and translocations suggest that survival is poorer in translocations, which may be because of the effect of the coexisting trisomy. The difference between the two survival curves was not statistically significant so it is not possible to draw any clinically useful conclusions from these observations. 
Data about life expectancy and cause of death are important for clinicians and families. They often form part of the information given to parents when their child is first diagnosed with a chromosome disorder. A prediction of poor life expectancy may influence decisions about resuscitation and also bonding between parent and child. It is desirable that this information should be up to date and comprehensive but this is often difficult in rare conditions. This information will serve as a useful guide to clinicians when discussing life expectancy with parents. It will enable a physician to be more optimistic about a child's life expectancy if they have a small deletion and no major congenital anomalies. It should, therefore, be used in conjunction with an assessment of the child's clinical status, including cardiac and renal investigations where clinically indicated.

We would like to thank the Chromosome Abnormality Database, and the cytogenetic laboratories, clinical genetics services, and clinicians who kindly contributed data to the survey. We would also like to thank the Wolf-Hirschhorn Syndrome Support Group for their support and participation and Professor D M B Hall for his helpful advice both during the study and in the preparation of this paper. This work has been funded by Action Research.

1 Hirschhorn K, Cooper HL. Apparent deletion of one chromosome (4 or 5) in a child with defects of midline fusion. Hum Chrom Newsl 1961;4:14.

2 Wolf U, Reinwein H, Porsch R, Schroter R, Baitsch H. Defizienz an den kurzen Armen eines Chromosoms $\mathrm{nr} 4$ Humangenetik 1965;1:397-413.

3 Wright TJ, Ricke DO, Denison K Abmayr S, Cotter PD, Hirschhorn K, Keinanen M, McDonald-McGinn D, Somer M, Spinner N, Yang-Feng T, Zackai E, Altherr MR. Somer M, Spinner N, Yang-Feng T, Zackai E, Altherr MR. A transcript map of the newly defined $165 \mathrm{~kb}$ Wolf1997;6:317-24.

4 Johnson VP, Mulder RD, Hosen R. Wolf-Hirschhorn (4p-) syndrome. Clin Genet 1976;10:104-12.

5 Wilson MG, Towner JW, Coffin GS, Ebbin AJ, Siris E, Brager P. Genetic and clinical studies in 13 patients with the Wolf-Hirschhorn syndrome $[\operatorname{del}(4 \mathrm{p})]$. Hum Genet 1981;59:297-307

6 Wilson MG, Towner JW, Negus LD. Wolf-Hirschhorn syndrome associated with an unusual abnormality of chromosome No 4. F Med Genet 1970;7:164.

7 Passarge E, Altrogge HC, Rudiger RA. Human chromosomal deficiency: the 4p- syndrome. Humangenetik 1970 10:51-7.

8 Estabrooks LL, Lamb AN, Aylesworth AS, Callanan NP, Rao KW. Molecular characterisation of chromosome $4 \mathrm{p}$ deletions resulting in Wolf-Hirschhorn syndrome. $f \mathrm{Med}$ Genet 1994;31:103-7.

9 Preus M, Ayme S, Kaplan P, Vekemans M. A taxonomic approach to the $\operatorname{del}(4 \mathrm{p})$ phenotype. Am f Med Genet 1985 ; 21:337-45.
10 Wieczorek D, Krause M, Majewski F, Albrecht B, Horn D, Riess O, Gillessen-Kaesbach G. Effect of the deletion and clinical manifestations in Wolf-Hirschhorn syndrome: analysis of 13 patients with a de novo deletion. Eur $\mathcal{F}$ Hum Genet 2000;8:519-26.

11 Zollino M, Di Stefano C, Zampino G, Mastroiacovo P, Wright TJ, Sorge G, Selicorni A, Tenconi R, Zappala A, Battaglia A, Di Rocco M, Palka G, Pallotta R, Altherr MR, Neri G. Genotype-phenotype correlations and clinical diagnostic criteria in Wolf-Hirschhorn syndrome. $\mathrm{Am} \mathcal{F}$ Med Genet 2000;94:254-61.

12 Meloni AM, Shepard RR, Battaglia A, Wright TJ, Carey JC. Wolf-Hirschhorn syndrome: correlation between cytogenetics, FISH, and severity of disease. Am f Hum Genet 2000;67(suppl 2):149.

13 Partington MW, Fagan K, Soubjaki V, Turner G. Translocations involving 4p16.3 in 3 families: deletion causing the Pitt-Rogers-Danks syndrome and duplication resulting in a new overgrowth syndrome. $\mathcal{F}$ Med Genet 1997;34:719-28.

14 Wright TJ, Clemens M, Quarrell O, Altherr MR. WolfHirschhorn and Pitt-Rogers-Danks syndromes caused by overlapping 4p deletions. Am F Med Genet 1998;75:345-50.

15 Wright TJ, Altherr MR, Callen D, Hirschhorn K. Reply to the letter to the editor by Partington and Turner "Wolf-Hirschhorn and Pitt-Rogers-Danks syndromes". Am 7 Med Genet 1999;82:89-90.

16 Francis B, Green M, Payne C. The GLIM system. Release 4 manual. Oxford: Clarendon Press, 1994.

17 Rigby AS. Statistical methods in epidemiology. III. The odds ratio as an approximation to the relative risk. Disabil Rehabil 1999;21:145-51

8 Morris JA, Gardner MJ. Calculating confidence intervals for relative risks (odds ratios) and standardised ratios and rates. $B M F$ 1990;296:1313-16.

19 Lurie IW, Lazjuk GI, Ussova YI, Presman EB, Gurevich DB. The Wolf-Hirschhorn syndrome. 1. Genetics. Clin Genet 1980;17:375-84.

20 Gorlin RJ, Cohen MM, Levin LS. Syndromes of the head and neck. New York: Oxford University Press, 1990:46-8.

21 Estabrooks LL, Breg WR, Hayden MR, Ledbetter DH, Myers RM, Wyandt HE, Yang-Feng TL, Hirschhorn K. Summary of the 1993 ASHG ancillary meeting "Recent research on chromosome $4 \mathrm{p}$ syndromes and genes". Am $\mathcal{F}$ Med Genet 1995;55:453-8.

22 Battaglia A, Carey JC. Update on the clinical features and natural history of Wolf-Hirschhorn syndrome (WHS): experience with 48 cases. Am F Hum Genet 2000;67(suppl 2):127.

23 Office of Health Statistics. Compendium of health statistics. 10th ed. London: BSC Print Ltd, 1997.

24 Office for National Statistics. Key population and vital statistics: local and health authority areas, 1998. Series VS, No 25, PP1 No 21. London: The Stationary Office, 1998.

25 Macfarlane A, Mugford M, Henderson J, Furtando A, Stevens J, Dunn A. Birth counts: statistics of pregnancy and childbirth. Vol 2, tables. London: The Stationary Office, 2000 .

26 Stec I, Wright TJ, van Ommen GJB, de Boer PAJ, van Haeringen, Moorman AFM, Altherr MR, den Dunnen JT. WHSC1, a $90 \mathrm{~kb}$ SET domain containing gene, expressed in early development and homologous to a Drosophila dysmorphy gene maps to the Wolf-Hirschhorn syndrome critical region and is fused to $\mathrm{IgH}$ in $\mathrm{t}(4 ; 14)$ multiple myloma. Hum Mol Genet 1998;7:1071-82.

27 Elder FFB, Colasurdo GN, Rose VM. Wolf-Hirschhorn/ Pitt-Rogers-Danks phenotype with no detectable deletion. Am F Hum Genet 2000;67(suppl 2):119.

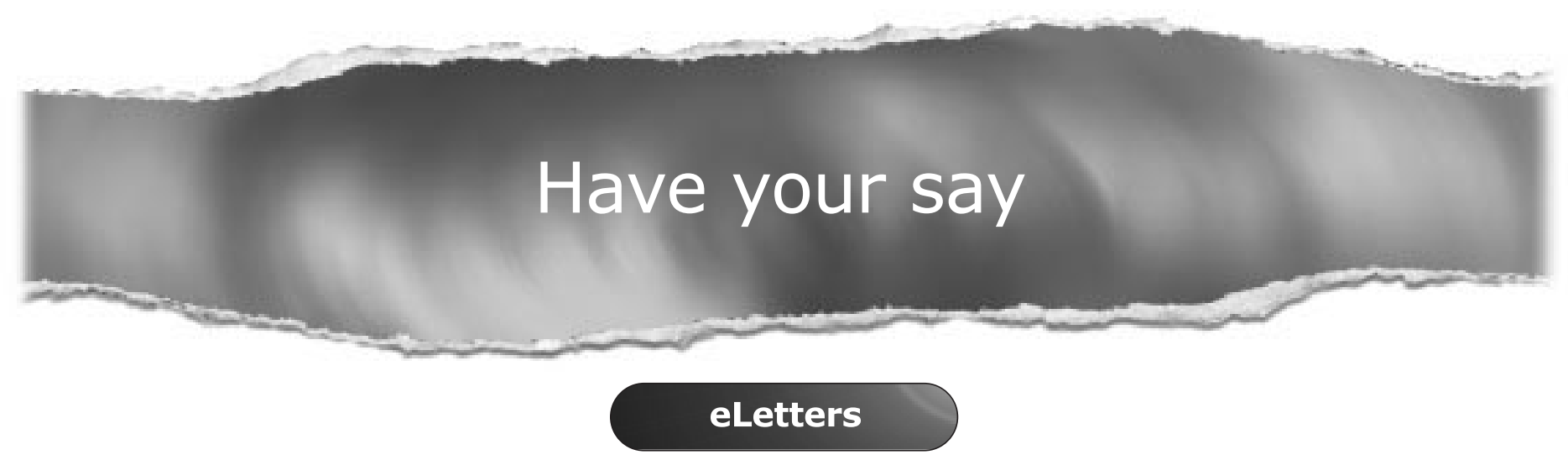

If you wish to comment on any article published in the Journal of Medical Genetics you can send an eLetter using the eLetters link at the beginning of each article. Your response will be posted on Journal of Medical Genetics online within a few days of receipt (subject to editorial screening). 